Rev. Latinoam. Psicopat. Fund., São Paulo, v. 12, n. 1, p. 228-232, março 2009

Estridente Strindberg

Gisálio Cerqueira Filho

Rio de Janeiro: NPL, 2008, volume 2.

\title{
Estridente Strindberg
}

Daniella Amaral Diniz da Silva

Composto de um ensaio e do prefácio em português e em alemão, e da tradução da peça $O$ pai de August Strindberg, Estridente Strindberg, de autoria de Gisálio Cerqueira Filho, traz mais uma valiosa contribuição para o campo da ciência política associado aos estudos da psicopatologia fundamental. Cientista político, sociólogo e humanista de longa data, Gisálio recorre mais uma vez ao uso de uma interpretação rica em detalhes da peça de Strindberg, utilizando o recurso à psicopatologia, como método de análise da dramaturgia de cunho intimista do autor sueco.

O recurso ao teatro, como universo para análise, torna-se interessante, do ponto de vista das referências estéticas, e crucial, para se absorver os aspectos simbólicos que envolvem arte e poder, criação e intenção artística e crítica. A peça $O$ pai, comentada e prefaciada por Gisálio, destaca-se ao expor de maneira aguda, "estridente", como o título sugere, a questão do autoritarismo e do absolutismo afetivo que circundam as relações familiares (na época, bem como nos dias de hoje). Strindberg, que influenciou diretamente a obra de Ingmar Bergman (1918-2007) - conforme Gisálio vem ressaltar -, trabalhou as relações de poder dentro do núcleo familiar e soube explorar na sua dramaturgia elementos subjetivos do cotidiano. Estes elementos convertidos em episódios que poderíamos chamar de manifestações de insuficiência imunológica psíquica - nos termos propostos por 
Manoel T. Berlinck (2000) - correspondem a sintomas que indicam estados psíquicos imbricados com estados físicos e orgânicos. Tais estados, ao serem analisados e submetidos à análise, servem como sintomas de manifestações do pensar, do agir e do sentir, que merecem investigações críticas no campo da ciência política.

Como método, a psicopatologia exige atenção e a imersão do pesquisador para se perceber aspectos da vulnerabilidade do indivíduo, que estão atrelados a um comportamento social e político específico. Através da observação de detalhes, a princípio irrelevantes, e da vivência de experiências sensoriais, o investigador percorre os traços mais leves e os aspectos mais sutis, que traduzem as relações de poder no universo mais íntimo do indivíduo. Estes aspectos e traços, que extravasam nas contradições e paradoxos das relações familiares, assumem um papel particularmente interessante na obra de August Strindberg.

Inserido num contexto histórico e político de destaque, Strindberg, que era sueco (tal qual Bergman), percorreu uma boa parte da Europa norte-ocidental, e incorporou algumas características-chave do intelectual e artista da virada para o século XX. Os conflitos e contradições, imersos no ambiente cultural da intelectualidade nesse período, que dizem respeito à conformação da identidade nacional, da identidade de classe (burguesa) e que envolvem as mudanças mais significativas no que tangem às relações entre Estado, Igreja e família, deveras atingiram muitos dos artistas contemporâneos a Strindberg. O drama existencial da peça $O$ pai acompanhou estas questões, seguindo os padrões estéticos e o formato da dramaturgia da época, promovendo no leitor a experimentação de uma sensação de sufocamento e introspecção que são trabalhadas por Gisálio no texto.

Para o leitor desavisado, a sensação despertada pela peça é de intenso desconforto. Semelhante talvez àquele provocado pela obra de Franz Kafka $O$ processo, $O$ pai promove o envolvimento do leitor (público) com o personagem principal, o capitão (Adolf), que, ao longo da peça, desenvolve um quadro de obsessão com a questão da paternidade de sua filha (Bertha). O personagem transmite a sensação de angústia e de que está sendo traído. Ambas as sensações se relacionam com a presença da esposa (Laura) na peça. A insegurança e a dúvida, questões centrais para Strindberg, permanecem através dos diálogos, com recorrentes perguntas sem respostas e elucubrações. A repetição da mesma dúvida "sou ou não sou o pai" acompanha o drama do início ao fim, colocando o leitor indeciso. A trama nos faz recordar Dom Casmurro (de Machado de Assis), embora o formato e padrão estéticos sejam diferentes (esta se dá em primeira pessoa, e não no formato de uma peça, tal qual $O$ pai). A trama consegue envolver o leitor num nível de proximidade com o personagem, de forma que ele se relaciona afetivamente com o público, e, com ele, chega a acompanhar as emoções que levam o personagem à loucura. 
Os demais personagens (com a exceção da esposa) exercem papéis que oscilam entre dúvida e impotência, e os diálogos travados pelos personagens Nojd e pela enfermeira Margret deixam escapar alguns aspectos da relação de amor e submissão, de sofrimento e gozo vivida no intimismo da peça de Strindberg.

Do ponto de vista analítico, a entrada para a leitura da peça $O$ pai se dá por quatro diferentes portas, anunciadas por Gisálio, no ensaio. São elas: 1) o absolutismo afetivo; 2) a ignorância simbólica da lei; 3) a misoginia; 4) a expiação da culpa a partir da encenação do sofrimento (p. 37). O objetivo é desvelar o que há de excesso e absolutista nas relações de poder encobertas pelo véu do afeto e circunscritas nas relações sociais e familiares.

O absolutismo afetivo torna-se transparente, na relação de autoridade e autoritarismo que se materializam na figura do capitão, no seu desejo de controle absoluto, de amor como posse e obediência suprema dos amados; percorre também a relação do capitão com a esposa, e os empregados, e o casamento como instituição indissolúvel, inatingível, reificada pelos símbolos de submissão e rendição ao outro. O casamento é retratado como uma prisão, uma relação doentia, manipulada pela figura da mulher, e da mãe, que detém o conhecimento e mantém-se sob o símbolo da incerteza. A máxima perinde ac cadaver (obediência como um cadáver) de Inácio de Loyola e dos jesuítas da Companhia de Jesus (p. 38), lida por Gisálio nas entrelinhas da peça, invoca os contornos religiosos dessas relações de poder. E invoca a relação do homem, como pai e marido, ao redor de um absoluto cuja obediência se faz pela anulação dos sentidos de ouvir e ver ("obediência cega e surda"), conforme menciona o próprio personagem do capitão.

A ignorância simbólica da lei, como entrada do texto, pode ser lida num desdobramento desse mesmo absolutismo afetivo, apontado por Gisálio. A imagem totêmica, conforme sugere, onipresente e avassaladora, se iguala a uma ausência, a um vazio afetivo. De absoluto torna-se abstrata a simbologia do pai e do marido. O controle completo do outro se configura numa abstração, numa ambivalência de extremos que anula a materialização. De tão grave, tão intenso, tão violento, tão "estridente", o poder se dilui e evapora. Simbolicamente, as repercussões da análise do autoritarismo, no viés da ignorância simbólica da lei, assumem contornos preciosos para a análise do poder na sociedade brasileira. Os excessos de submissão e absolutismo que Gisálio vem trabalhando na investigação do fenômeno sociopolítico da violência no Brasil se tornam exemplarmente vivos na leitura da peça. O capitão de $O$ pai pode encontrar paralelos nas relações de poder da figura paterna representada pelo Estado e metaforizada nas relações familiares. $\mathrm{O}$ autoritarismo, resumido pela obsessão pelo controle total e irrestrito não assegura a paternidade do capitão. A dúvida, que ele não consegue responder é: como se pode ser pai, se o desejo de controle absoluto ultrapassa a materialidade das relações humanas? 
A misoginia, enquanto temática e recorrência no aprofundamento das questões de poder, também é uma das entradas mais visíveis e mais nítidas da peça, observadas também por Gisálio. O signo da misoginia vem com a caracterização dúbia ou ambígua que se associa com o gênero feminino a partir do personagem principal com sua esposa. Não somente pela dúvida sobre a paternidade que acompanha a obsessão do capitão ao longo do texto, mas também pela associação da performance desempenhada pelos personagens femininos com características de dubiedade, entre a obediência e a insurgência, entre a fidelidade e a traição. Não somente a esposa, mas também a enfermeira, com quem o capitão desenvolve, pelo afeto, o desejo de submissão e a perda do controle, a partir do qual exacerba sua loucura.

Por fim, a expiação da culpa a partir da encenação do sofrimento, enquanto entrada para o texto da peça, retoma, ao mesmo tempo, pelo viés religioso, a relação de dor, autoflagelo, prazer e redenção, que atravessam a relação de poder e que podem ser enxergados exemplarmente na atuação dos empregados, Margret e Nodj. Além de confirmar a dicotomia que atravessa toda a peça (ser ou não ser pai, obedecer ou não obedecer, amar ou não amar, intervir ou não o capitão), ambos decidem em favor da esposa, pela intervenção de Adolf. Ambos, requisitados por Laura exatamente pelo afeto pelo capitão e pelo acesso mais fácil ao superior, hesitam num primeiro momento, mas decidem por concordar e ajudar a imobilizá-lo na camisa de força. O gesto é associado à prática de amor, a uma manifestação de sofrimento com intenções afetivas, por parte de ambos. Socialmente, ambos representam empregados, função de subordinação e obediência. Entretanto, até que ponto a reação e o ato voluntário de concordância com Laura não podem representar exatamente a liberação, a exacerbação de um prazer (exercitado na sensação de culpa, manifestada pelas repetidas frases de Margret), de vingança e revogação da submissão ao poder autoritário do "pai"? A peça se inicia exatamente com a discussão, projetada para o empregado Nodj, de quem o capitão e o pastor querem cobrar uma atitude, depois de acreditarem que ele tenha engravidado uma moça da região. De maneira enfática, o capitão exige que o pastor faça uso do poder de confessor e autoridade para aplicar um castigo ao empregado (poder esse que o próprio capitão irá negar, por se crer ateu e avesso a crenças religiosas). É a partir da dúvida suscitada pelo próprio Nodj que toda a insegurança do capitão começa a se desenvolver. Margret, como veículo de retomada e ligação de Adolf entre afeto e razão, ao mesmo tempo trai de fato o seu desejo, repetidamente obedece ao patrão, mas de forma sutil o trai, quando se coloca afetivamente no comando das ações contra o desejo do capitão. Juntamente com a esposa e a filha, que, mais ao fim da peça, vem a materializar a traição, reificam o que Strindberg sustenta como a lógica fundamental da obra. A ideia de duplicidade, que acompanha a caracterização do capitão acerca do universo feminino, é também o elemento que 
decide, pela intervenção e, em última instância, pela própria morte. O absolutismo de Adolf não aceita a dúvida e sucumbe à morte. Em diálogo com a filha, $o$ personagem de Adolf (capitão) extravasa seu absolutismo num momento, quando, ameaçado e fora de si, se dirige à filha: "Mas você deve apenas me amar! Você deve ter uma alma ou nunca terá paz, nem eu tampouco. Você precisa apenas ter um pensamento que é filha do meu pensamento; você deve ter uma vontade que é a minha" (p. 106).

É esta a imagem, em última instância, que, até ser verbalizada, acompanha muitas das relações de poder, afetivas e formais, instituídas ou não. A fala que atravessa o discurso do poder e da autoridade, o desejo do absoluto, do completo, do ideal, do perfeito e transcendental, que ultrapassa os limites do humano (imperfeito). O que muitas vezes não pode ser captado ou percebido senão pela vivência da loucura, da perda da consciência completa da racionalidade, episódios da insuficiência imunológica psíquica, muitas vezes escapam e vêm à tona, de maneira mais sutil, no discurso, nos gestos e na performance social. Entretanto, na maior parte das vezes, o absolutismo afetivo que acompanha as relações sociais (familiares, políticas) não chega ao extremo da loucura, tampouco ao exagero sugerido na peça; atravessa as relações no nível do aceitável, e passa desapercebido ao olhar crítico do leitor e do investigador social.

Strindberg, que esteve preocupado em traduzir o sofrimento (pathos) das relações afetivas às quais ele mesmo se submeteu com algum grau de absolutismo, soube, através do recurso à dramaturgia, imergir o leitor numa experiência sensorial e psíquica que percorresse o caminho dos personagens num grau de intimismo e envolvimento. Do ponto de vista analítico das questões relativas à teoria política, o recurso à estética do teatro, escolhido por Gisálio, oferece novamente uma atualização metodológica de uma temática cuja importância não se esgota nos dias atuais. Strindberg, como autor do século XIX, continua atual e vivo, muito mais além das questões estritamente individuais no âmbito do poder. Ao falar do pai, e da obsessão pela paternidade, Strindberg também fala do sofrimento provocado pelo desejo de mandar, de fazer-se soberano, absoluto, imortal, embora morto.

\section{Daniella Amaral Diniz da Silva}

Bacharel em Ciências Sociais pela Universidade Federal do Rio de Janeiro - UFRJ (Rio de Janeiro, RJ, Brasil); mestre em História pela Universidade Federal Fluminense - UFF (Niterói, RJ, Brasil), aluna do doutorado do programa de Espanhol e Português na Universidade de Columbia.

Rua Voluntários da Pátria, 305/106 - Botafogo

22270-000 Rio de Janeiro, RJ, Brasil

e-mail:dani_ads@yahoo.com.br 